\title{
A quantitative calculation approach research of tooth surface friction characteristic parameters
}

\author{
Shuang Xue $\mathrm{Fu}^{\mathrm{a}}$ \\ Guangzhou Civil Aviation College, Guangzhou, Guangdong, 510403, China
}

\begin{abstract}
A new calculation approach of tooth surface friction characteristic parameters is raised in this paper, the caclulation approach is based on gear drive test experience and finite element multi field coupling analysis method and technology.In the process of solution, friction characteristic concept of engineering oriented complex gear drive is raised, "experiment- calculation composite model" is built, tooth surface friction characteristic parameters(friction coefficients) are inversely analyzed by the composite model under different lubrication conditions. The problem of complicated tooth friction coefficients is solved. The calculation method is a new idea on solving friction characteristic parameters under complex lubrication conditions, it unites theoretical research, system modeling, numerical simulation and experimental test, so its solution is more reasonable. Exactly research friction coefficients can help to search gear friction principle and to upgrade the level of decrease noise and vibration of gear.
\end{abstract}

Key words: Friction chracteristic parameters; Quantitative calculation; Composite model; Lubrication ; Gear drive.

\section{Introduction}

The research of the tooth surface friction to reduce friction, increase the load capacity of gear tooth, and improve the system transmission performance has very important significance. Studies have shown that [1-5], the tooth surface friction contribute to the formation of pitting, tooth root crack initiation and extension, and increase effect of tooth fracture. Due to tooth surface friction, the formation of pitting, tooth root crack initiation and extension and tooth fracture are intensified. At the same time, the tooth surface friction affects the dynamic characteristics of gear transmission system, it is an important origin of vibration and noise excitation [614].The tooth surfaces friction coefficients are exact solution has positive significance on gear fatigue strength design, failure mechanism analysis, and damping and noise-reducing. on account of the gear drive characteristics of dynamic, randomness and chaos under the complex lubrication conditions, Based on the gear drive dynamic measurement experiment, finite element method(FEM) multi-field coupled analysis and inverse computation technology are used, the complex gear drive " polymorphous friction " concept was put forward.

The experiment-simulation composite model of complex gear drive is built. Based on the composite model, the friction coefficient of the upper dividing point of single contact is solved. The theory research, system modeling, numerical simulation and experimental test are applied to the composite model, the tooth face friction coefficients are quantified calculation. It can help to perfect the calculation method of tooth surface friction coefficient, provide a reference basis for building a tooth surface friction coefficient calculation theory system.

\section{Polymorphous modeling of gear drive}

In the process of tooth meshing, its friction mechanism is extremely complex. In the tooth meshing range, the lubrication condition and change rule of friction process are shown as followed:

\footnotetext{
a Corresponding author: 25272505@qq.com
}

(1) In lubrication gear drive: engaging-in impact friction $\rightarrow$ transition friction (boundary friction, mixed friction) $\rightarrow$ elastic-hydrodynamic lubrication $\rightarrow$ transition friction (boundary friction, mixed friction) $\rightarrow$ engagingout impact friction;

(2) Without lubrication or self-lubricating gear drive: engaging-in impact friction $\rightarrow$ dry friction $\rightarrow$ engagingout impact friction.

Based on the physical process, the complex gear drive "polymorphous friction" concept was put forward. The main purpose of this study is to find out the actual meshing tooth surface complex frictional conditions and its change rules, provide key technical support for the gear drive tribology precise design

The complex gear drive "polymorphous friction" concept, is refers to the two tooth meshing contact surfaces or friction medium (such as lubricating oil slick) explicit characteristics and status in the process of the relative movement. The experiment-simulation composite model of complex gear drive polymorphous friction process analysis and quantitative research is built. (As shown in Figure 1). This model is mainly composed of experiment and simulation module. Experiment module includes: the complex gear drive test system, the data acquisition system, the characteristic parameter extraction mechanism, etc. Simulation module includes: the inverse analysis algorithms, the finite element method (FEM) analysis, and Intergeneration Projection Genetic Algorithm (IP - GA) [15], etc. The model will be used to systematically research the friction distribution characteristics and its change rules under different lubrication conditions. 


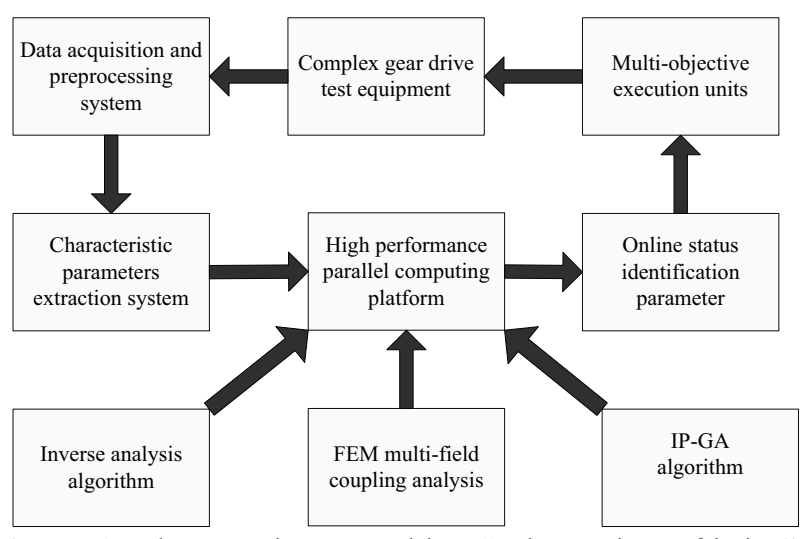

Figure 1. The complex gear drive "polymorphous friction" modeling

\section{The test principle and experiment table}

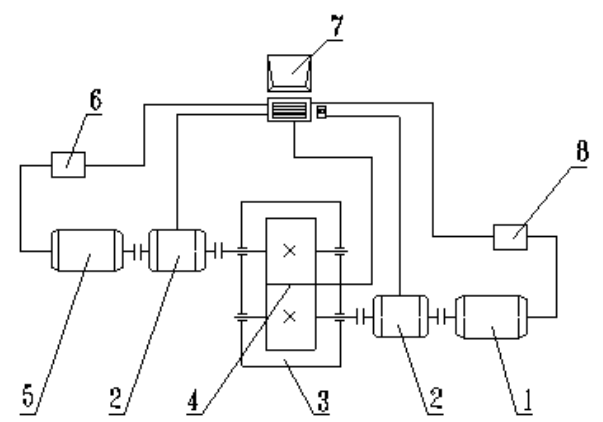

1. magnetic loader, 2. speed torque sensor, 3. gear box and gears,4. resistance strain gauge, 5. motor, 6. converter, 7.computer, 8. load controller

Figure 2. The test principle figure of acquiring key parameter

According to the mapping principle of between the force field of meshing tooth non-contact sensitive area and the tooth surface friction force, sensitive area stress and strain test scheme is designed, dynamic measurement experiment device (see Figure 2)is developed, the characteristic parameters (stress or strain of tooth root stress sensitive areas)are extracted, and the experiment table is shown in Figure 3. The location of the sensitive area can be determined by the finite element analysis of gear and photo-elastic experiment conclusion.

The system structure and working principle of extraction key characteristic parameters experiment device are expressed that:

The test gears 3 is driven by converter motor 5 , the load of gear teeth will be adjusted by the magnetic loader 1 and load controller 8,the variable-speed motor and continuous variable load loaders are controlled by the computer system 7, The tooth stress and strain of sensitive area are measured by resistance strain gauge 4 . The test signals are amplified by the amplifier and output to the dynamic data acquisition cards by mercury slip ring, the experimental gear box 3 temperature is controlled by the cooling system, the meshing teeth lubrication state is adjusted by the lubrication system. The extracted characteristic parameters are imported high-performance parallel computing system 7, and thus inverse analysis algorithm is run.

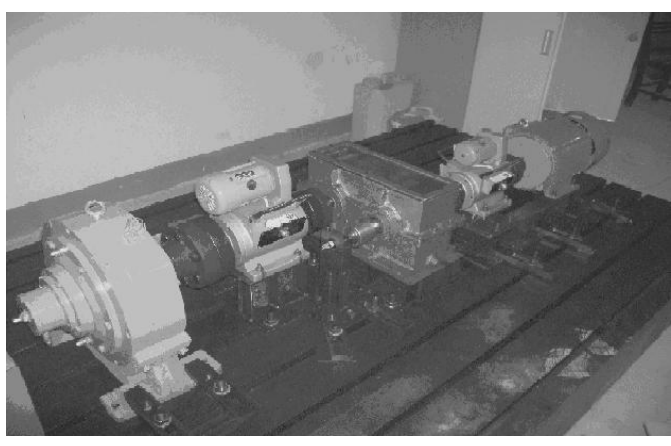

Figure 3. The experiment table of acquiring key parameter

\section{Inverse analysis process of the meshing tooth surface friction characteristic parameters}

The friction coefficient inverse analysis scheme is shown in Figure 4. In a certain lubrication condition, the Characteristic parameters (the strain sequence $\varepsilon^{\prime}$ of tooth root stress sensitive area) will be extracted by the experimental modules, the FEM multi-field coupling analysis parameter strain sequence $\varepsilon$ in the same positions is calculated, The objective function $\mathrm{F}(\mu)$ whose independent variable is coefficient friction $\mu$ is built, the search area of the friction coefficient is set under the lubrication condition, the IP-GA is adopted to deduced the tooth face friction coefficient $\mu$.

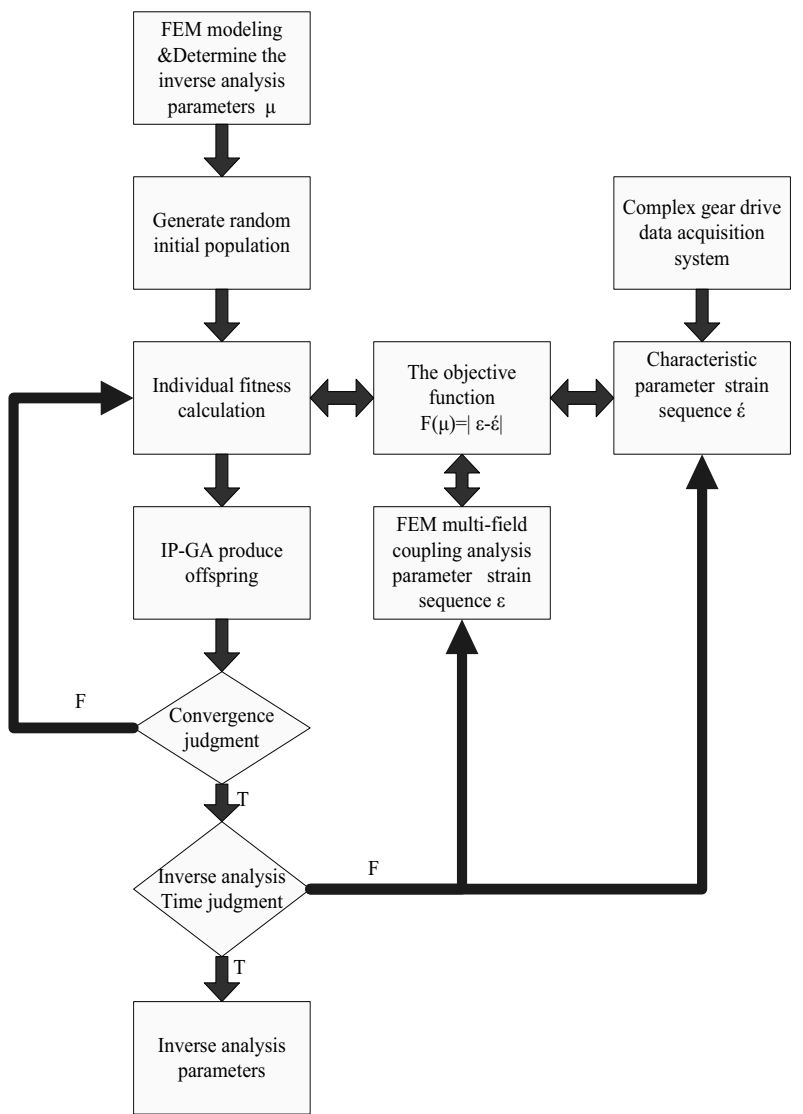

Figure 4. The flow chart of tooth friction characteristic parameters inverse analysis 


\section{The example of inverse analysis}

\subsection{Parameters of gear and material characteristic of gear}

The transmission ratio of two meshing gears is 1 , and the gear precision is grade 6 . Tooth profile error and the deformation of axis and gearbox are ignored. Gear parameters are given in Table 1. The material of gear is 45\# steel, its parameters shown in Table 2. Rotation speed $n_{1}$ is $100 \mathrm{r} / \mathrm{min}$ and transmission power $P$ is $5.6 \mathrm{kw}$.

Table 1.Parameters of gear

\begin{tabular}{|c|c|c|}
\hline Tooth numbers & $\boldsymbol{Z}$ & $30 / 30$ \\
\hline Modulus & $\boldsymbol{m} / \mathrm{mm}$ & 6 \\
\hline Axis diameter & $d_{0} / \mathrm{mm}$ & 50 \\
\hline Pressure angle & $\alpha /\left(^{\circ}\right)$ & 20 \\
\hline $\begin{array}{c}\text { Addendum } \\
\text { coefficient }\end{array}$ & $x / \mathrm{mm}$ & 0 \\
\hline $\begin{array}{c}\text { Tooth width } \\
\text { Totmm }\end{array}$ & 60 \\
\hline
\end{tabular}

Table 2. Material characteristic of gear

\begin{tabular}{|c|c|c|}
\hline Material & & $45 \#$ \\
\hline Elastic modulus & $\boldsymbol{E} / \mathrm{GPa}$ & 204 \\
\hline $\begin{array}{c}\text { Shearing } \\
\text { modulus }\end{array}$ & $\boldsymbol{G} / \mathrm{GPa}$ & 79.6 \\
\hline Poisson's ratio & $\boldsymbol{v}$ & 0.3 \\
\hline Density & $\boldsymbol{\rho} / \mathrm{kg} . \mathrm{m}-3$ & 7847 \\
\hline
\end{tabular}

According to gear engagement curve formulas[16], the exact position coordinates of the points on tooth profile are solved in MATLAB (see Figure 5) and written into a full text date file. The file is imported as APDL (ANSYS Parametric Design Language) procedure, and then theoretical tooth profile is attained in ANSYS, the tooth profile is shown in Figure 6, and the tooth geometric model is built in ANSYS, it is shown in Figure 7.According to the analysis results of the paper [17], based on the requirements of design precision, the boundaries of gear model are reasonably determined, this paper adopts three tooth model and the gear tooth meshing model is shown in Figure 8.

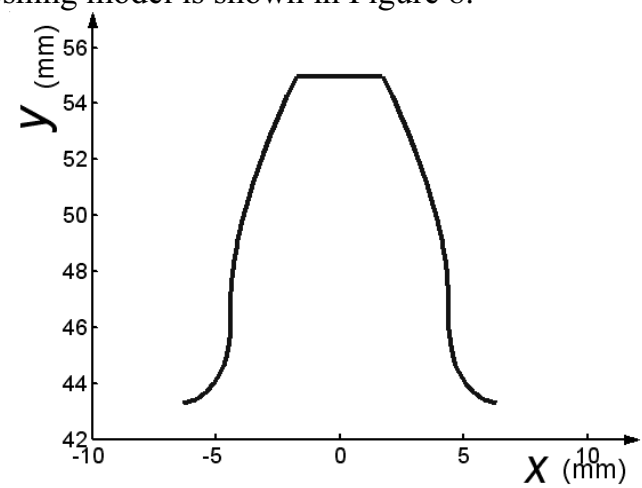

Figure 5. The tooth profile in MATLAB

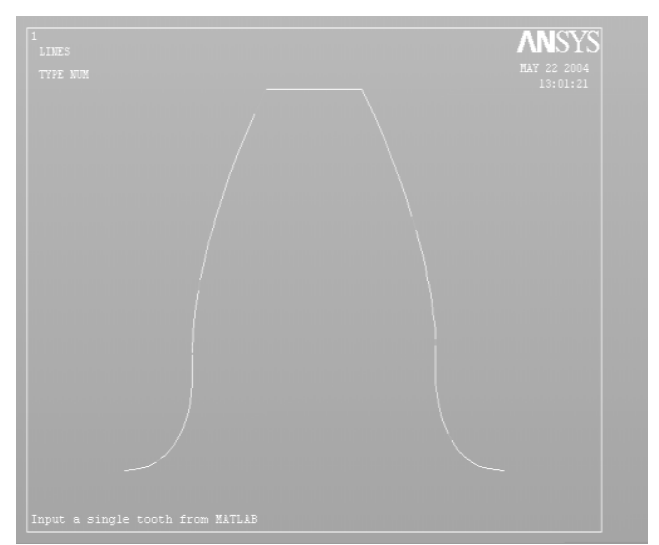

Figure 6. The tooth profile in ANSYS

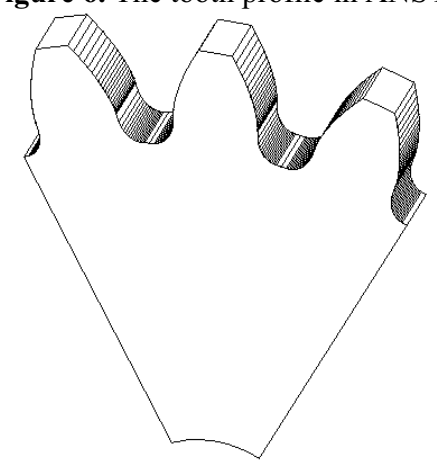

Figure 7. The tooth geometric model in ANSYS

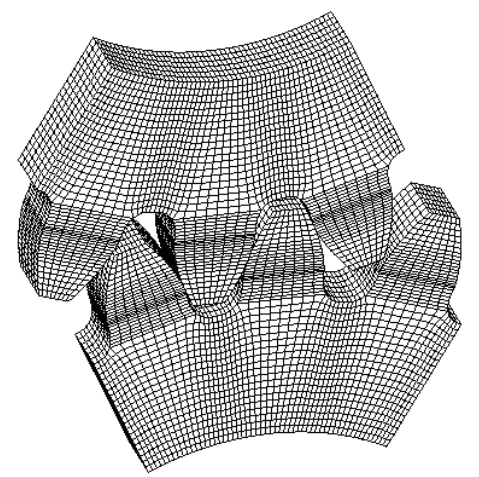

Figure 8. Gear meshing FEM model

\subsection{Tooth face friction characteristic parameters inverse analysis}

The input parameter sensitivity analysis must be done before inverse analysis. According to FEM analysis and the photo-elastic experiment conclusion, the maximum stress/strain section in the gear tooth root transition-curve is regarded as a sensitive area. According to study conclusion of paper[8], it is very sensitive between the tooth face friction coefficient and tooth root stress/strain. In general, the tooth face friction coefficient is influenced by lubrication conditions. According to study conclusion of paper[18],the inverse analysis of the tooth face friction characteristic parameters (tooth face friction coefficients) are done under boundary lubrication and mixed lubrication conditions. The convergence trends of friction coefficients inverse analysis are shown in Figure 9.The inverse analysis results are shown in Table 3. 


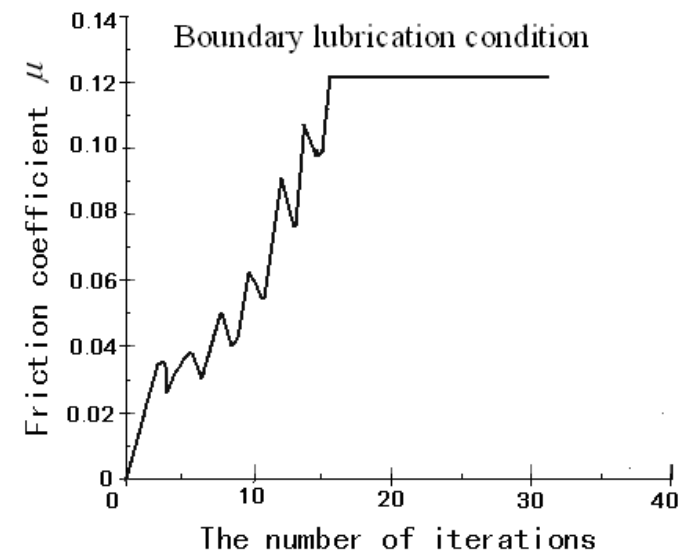

(a)

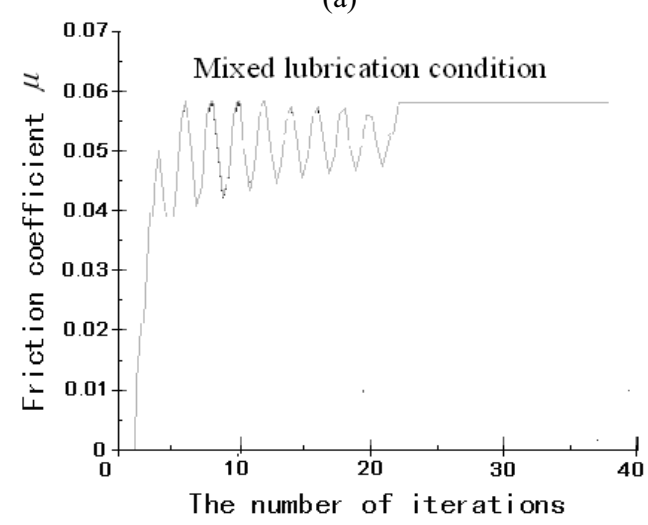

(b)

Figure 9. The convergence trends of friction coefficients inverse analysis under different lubrication conditions

Table 3. The inverse analysis results under two kinds of lubrication conditions

\begin{tabular}{|c|c|}
\hline Lubrication conditions & Friction coefficient \\
\hline Boundary lubrication condition & 0.120 \\
\hline Mixed lubrication condition & 0.060 \\
\hline
\end{tabular}

The tooth face friction coefficient inverse analysis is based on dynamic gear drive experiment, the input parameter is tooth root strains, FEM multi-field coupled analysis is used at the same time. It can truly simulate the actual working condition, and based on the fast convergence and global optimization mechanism Properties of IP-GA, the inverse analysis values of the friction coefficients are very precise. Under boundary lubrication condition, the inverse analysis value is 0.120 , under mix lubrication condition, the inverse analysis value is 0.060 , and they conform to the conclusions of paper[18],the values are reliable.

\section{Summary}

(1)The complex gear drive " polymorphous friction " concept was put forward and the experimentsimulation composite model of complex gear drive is built.

(2)The theory research, system modeling, numerical simulation and experimental test are applied to the experiment-simulation composite model of complex gear drive, the tooth face friction coefficients can be quantified calculation.

(3)It can help to perfect the calculation method of tooth surface friction coefficient, provide a reference basis for building a tooth surface friction coefficient calculation theory system.

\section{Acknowledgments}

The authors gratefully acknowledge the support of training program of Guangdong province outstanding young teachers in colleges and universities (YQ2014178).

\section{References}

1. Flašker J, Fajdiga G, Glodez S, et al. 2001. Numerical simulation of surface pitting due to contact loading. International Journal of Fatigue, 23(7) :599-605.

2. Lewicki D G, Handschuh R F, Spievak L E, et al. 2001. Consideration of moving tooth load in gear crack propagation predictions. ASME Journal of Mechanical Design, 123(3) :118-124.

3. Vedmar L, Henriksson B. 1998. A general approach for determining dynamic forces in spur gears. ASME Journal of Mechanical Design,120(12) :593-598.

4. Velex P, Cahouet V. 2000. Experimental and numerical investigations on the influence of tooth friction in spur and helical gear dynamics. Journal of Mechanical Design, 122(12) :515-522.

5. Aziz S M A, Seireg A. 1994. A parametric study of frictional noise in gears. Wear, 176(1) :25-28.

6. Velex P, Sainsot P. 2002. An analytical study of tooth friction excitations in errorless spur and helical gears. Mechanism and Machine Theory, 37(7) :641658.

7. Litvin Faydor L, Fuentes Alfonso, Hayasaka Kenichi. 2006. Design, manufacture, stress analysis and experimental tests of a low-noise endurance spiral bevel gears. Mechanism and Machine Theory, 41(1):83-118.

8. Ajmi M, Velex P. 2005. A model for simulating the quasi-static and dynamic behavior of solid widefaced spur and helical gears. Mechanism and Machine Theory, 40(2) :173-190.

9. Li S T. 2007.Finite element analyses for contact strength and bending strength of a pair of spur gears with machining errors, assembly errors and tooth modifications. Mechanism and Machine Theory, 42(1): 88-114.

10. Lewicki D G, Handschuh R F, Spievak L E, et al. 2001. Consideration of moving tooth load in gear crack propagation predictions. ASME Journal of Mechanical Design, 123(3):118-124.

11. Wang Feng,Fang Zongde,Wang Kanwei. 2014. Dynamics meshing efficiency of herringbone gears under mixed elastohydrodynamic lubrication condition. Journal Vibration and Shock, 33(16):150154. 
12. Zhang Jing, Chen Bingkui, Kang Chuanzhang, et al. 2012.Dynamic analysis for spur gears considering friction effect. Journal Vibration and Shock, 31(21):126-132.

13. Liu Changzhao,Qin Dalong,Liao Yinghua. 2014. Dynamic model for a parallel-axis helical gears transmission system based on variable friction coefficient between contact teeth. Journal Vibration and Shock, 33(24):150-157.

14. Pan Dong,Zhao Yang,Li Na,etal. 2012.The wear life prediction method of gear system. Journal of Harbin Institute of Technology, 44(9):29-33.

15. G R Liu, X Han.2003. Computational inverse techniques in nondestructive evaluation. New York: CRC Press.

16. Fu Shuangxue. 2008.Computational inverse studies of tooth friction coefficients in gear drive. Changsha: Hunan University College of Mechanical and Vehicle Engineering.

17. Zhou Changjiang, Tang Jinyuan, Zhong Zhihua et al.2005. Research on boundary of exact modeling of gear by FEM. China Mechanical Engineering, 16(22):2044-2049.

18. Editor committee of gear handbook.2006. Gear handbook. 2nd.Beijing:China Machine Press. 